\title{
The Oceans and Human Health: The Discovery and Development of Marine-Derived Drugs
}

\author{
Shirley A. Pomponi \\ Harbor Branch Oceanographic Institution - Fort Pierce, Florida USA
}

\begin{abstract}
Introduction
I am honored to have been invited to present the Second Annual Roger Revelle Commemorative Lecture. Although I never had the opportunity to meet or work with Dr. Revelle, his depth and breadth of knowledge and scientific investigations have inspired and challenged oceanographers to interpret the results of their research in the context of systems, rather than as isolated phenomena. It is with this challenge in mind that I will discuss the role of the oceans in human health, and specifically, challenges in realizing the potential for the discovery of new, marine-derived drugs to treat human diseases.
\end{abstract}

\section{Nature as a Source of Drugs}

For thousands of years, man has taken advantage of nature's ability to produce remedies to treat infection, inflammation, pain, and many other diseases and ailments. In some parts of the world, natural medicines are still the only treatments available. Scientific research on these ethnomedicinal preparations led to the discovery of purified chemicals, whose beneficial properties provided the foundation of the current pharmaceutical industry. Today, over $50 \%$ of the marketed drugs are either extracted from natural sources or produced by synthesis using natural products as templates or starting materials. Drugs such as morphine, Taxol", aspirin, penicillin, vincristine, and cyclosporin are but a few examples of drugs derived from terrestrial plants and soil microorganisms (Balandrin et al., 1985). The recent emphasis on "alternative" medicines by the National Institutes of Health acknowledges both the history and importance of natural products in the treatment of diseases.

Based on the success of Bergmann and colleagues in the late 1950's (Bergmann and Burke, 1955), which led to the development of two drugs based on marine sponge nucleosides (Ara-A for herpes infections and Ara-C for leukemia) (Baker and Murphy, 1981), as well as the pioneering research in marine natural products drug discovery by the Roche Research Institute of Marine Pharmacology during the mid-1970s (McConnell et al., 1994), scientists began to explore the chemical diversity found in marine organisms and the potential for discovery of new drugs from the marine environment. What has become an intense effort in marine natural products drug discovery by academic, government, and industry laboratories, especially in the past 15 years, is based on a number of facts. The oceans are a rich source of both biological and chemical diversity. They cover more than $70 \%$ of the earth's surface and contain more than 200,000 described species of invertebrates and algae (Winston, 1988). It is estimated that this number is only a small percentage of the total number of species that are yet to be discovered and described (Malakoff, 1997). Marine microorganisms represent the greatest percentage of undescribed marine species (Colwell, 1996). A relatively small number of marine organismsprimarily algae and invertebrates-has already yielded thousands of novel chemical compounds (Ireland et al., 1993), yet only a small percentage of these chemicals has been studied for their potential as useful products. Finally, although there is a major effort by pharmaceutical companies in the design of synthetic chemicals for drug discovery, marine natural products still provide unusual and unique chemical structures upon which molecular modeling and chemical synthesis of new drugs can be based.

Prosented at the U.S. National Academy of Sciences, Washington D.C. on 9 Nowimber 2000 . 
Why do marine plants, animals, and microbes produce chemicals that are useful as pharmaceuticals? Many of them are sessile-attached to the bottom-and they live in densely populated habitats where competition for resources, such as space and food, is intense. As a result, they have evolved a unique inventory of metabolites used for their defense, reproduction, and communication (Paul, 1992; Pawlik, 1993; Morse and Morse, 1991). These metabolites also interact with receptors and enzymes involved in human disease processes. If, for example, a sponge is trying to prevent another sponge from invading its space, it may produce a chemical to prevent the other sponge's cells from growing and dividing. It is not unusual, therefore, that these same chemicals may also be effective in inhibiting the uncontrolled growth of cancer cells.

In fact, a major emphasis has been on the discovery of marine-derived anticancer compounds, due in large part

TABLE I

Anti-tumor agents from marine sources that are currently licensed for development

Organism
Bryozoan:
Bugula neritina
Sea hare:
Dolabella auricularia
Tunicate:
Ecteinascidia turbinata

Metabolite

Bryostatin I

Dolastatin 10

Ecteinascidin 743

Tunicate:

Aplidium albicans

Gastropod:

Elysia rubefescens

Sponge:

Discodermia dissoluta

Sponge:

Lissodendoryx sp.

Actinomycete:

Micromonospora marina

Tunicate:

Didemnum granulatum

Sponge:

Jaspis sp

Sponge:

Cymbastella sp.

Sponge:

Pseudaxinyssa cantharella
Dehydro-didemnin B [Aplidine]

Kahalalide $F$

Discodermolide

Isohomo-

halichondrin B

Thiocoraline

Isogranulatimide

Hemiasterelins

$A \& B$

Girolline
Caribbean

Location

Gulf of California

Indian Ocean

Caribbean

Atlantic [Brazil]

New Zealand

Mozambique Strait

Canedo, Spain

Andersen \& Bjerinck, Univ, British

Columbia \& Brazil

Crews et al. Univ. California, Santa Cruz

Papua New Guinea

\author{
Discoverer \\ Pettit, \\ Pettit, \\ Arizona State Univ. \\ Rinehart, Univ. Illinois
}

Gunasekera \& Longley, $\mathrm{HBOI}$

Munro \& Blunt;

Univ. Canterbury, NZ

Andersen, Univ.

British Columbia

New Caledonia

Potier, France

\section{Current Status}

In Phase I/II clinical trials in

US/Europe; $\mathrm{NCl}$ sponsored trials.

Phase I clinical trials in US;

$\mathrm{NCl}$ sponsored trials.

Licensed to PharmaMar S.A. In Phase II clinical trials in Europe and in US.

Licensed to PharmaMar S.A.

Licensed to PharmaMar S.A.

Licensed to Novartis.

Licensed to PharmaMar S.A.

Licensed to PharmaMar S.A.

Licensed to Kinetik, Canada.

Synthetic derivative licensed to Novartis.

Licensed to Wyeth-Ayerst. Licensed to Rhone Poulenc. 
to the availability of funding to support marine-derived cancer drug discovery. The National Cancer Institute (NCI) has led this effort through its programs to support both single-investigator and multi-institutional natural products-based, cancer drug discovery research. As a result, several marine-derived compounds are in preclinical or clinical trials for the treatment of cancer as shown in Table 1. I will highlight just a couple.

Ecteinascidin 743, a complex alkaloid derived from the mangrove tunicate Ecteinascidia turbinate (Wright et al., 1990; Rinehart et al., 1990) shown in Figure 1 and licensed by the University of Illinois to PharmaMar S.A., is in Phase II clinical trials in the U.S. and Europe for the treatment of cancer. Discodermolide, a polyketide isolated from deep-water sponges of the genus Discodermia shown in Figure 2, inhibits the proliferation of cancer cells by interfering with the cell's microtubule network (ter Haar et al., 1996) as shown in Figure 3. This compound has been licensed by Harbor Branch Oceanographic Institution (HBOI) to Novartis Pharmaceutical Corporation, and is in advanced preclinical trials.



Figure 1. The tunicate, Ecteinascidia turbinata, source of ecteinascidin 743 , is a common inhabitant of mangrove roots throughout the tropical western Atlantic region (photo by John Reed, Harbor Branch Oceanographic Institution).

Despite the emphasis on identifying new anticancer compounds, marine natural products have also been found to have other biological activities, including mediation of the inflammatory response. The pseudopterosins are glycosides derived from the Caribbean soft coral Pseudopterogorgia elisabethae (Roussis et al., 1990). These are in advanced preclinical trials as antiinflammatory and analgesic drugs, and purified extracts of this soft coral are available commercially as additives in skin care products. Other marine-derived compounds, such as the prostaglandins, palytoxin, calyculin, okadaic acid, and manoalide, to name just a few, are available commercially as biomedical research probes that give us valuable insights into understanding and treating human diseases.

There are more than 10,000 scientific publications related to marine natural products (Munro et al., 1999). This fact serves to underscore the vast potential of the oceans as a source of novel chemicals with potential not only as pharmaceuticals, but also as nutritional supplements, cosmetics, agrichemicals, molecular probes, enzymes and fine chemicals shown in Table 2. Algal products alone form the basis for a multi-billion dollar industry (Radmer, 1996). Recognizing this potential, U.S. President Clinton issued a directive to the Secretary of Commerce on June 12, 2000, requesting recommendations for a national ocean exploration strategy. The President emphasized consideration of the full array of benefits the oceans provide, with "mechanisms to ensure that newly discovered organisms or other resources with medicinal or commercial potential are identified for possible research and development".

I will, therefore, focus the rest of my lecture on the challenges facing discovery and development of new marine organisms with medicinal potential. These challenges are technical, such as exploring new environments and developing new platforms, tools, and assays to discover and test organisms never before studied; financial, such as obtaining adequate support for both exploration and early-phase, high risk discovery research; and political, such as complying with regulations related to the rights of a country to its natural resources, as well as fair and equitable sharing of technologies and revenues resulting from commercialization of products from marine resources. Successful discovery and development of marine-derived pharmaceuticals will depend, of course, on our ability to address a number of scientific questions. What organism produces the bioactive compound, and why? Can we apply this knowledge to our rapidly increasing understanding of the human genome and human disease processes? Are there viable alternatives to prevent over-exploitation and ensure sustainable use of marine resources for drug development? Let's examine each of these challenges.

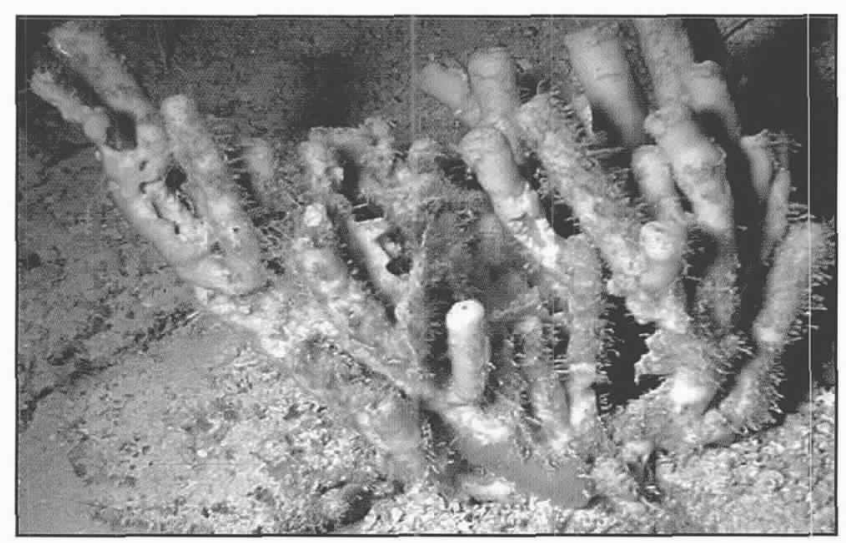

Figure 2. The sponge, Discodermia dissoluta, source of discodermolide, rarely occurs in shallow water, and is more commonly found at depths of 150-250m throughout the tropical western Atlantic region (photo courtesy of Harbor Branch Oceanographic Institution). 
TABLE 2

Some examples of commercially available marine bioproducts (adapted from Pomponi, 1999).

\begin{tabular}{|c|c|c|c|}
\hline$\frac{\text { Product }}{\text { Ara-A }}$ & $\frac{\text { Application }}{\text { antiviral drug }}$ & $\begin{array}{l}\text { Original Source } \\
\text { marine sponge, } \\
\text { Cryptotethya cryta }\end{array}$ & $\begin{array}{l}\text { Method of Production } \\
\text { microbial fermentation } \\
\text { of analog }\end{array}$ \\
\hline Ara-C & anticancer drug & $\begin{array}{l}\text { marine sponge, } \\
\text { Cryptotethya cryta }\end{array}$ & chemical synthesis of analo \\
\hline okadaic acid & $\begin{array}{l}\text { molecular probe: } \\
\text { phosphatase inhibitor }\end{array}$ & dinoflagellate & cell culture \\
\hline manoalide & $\begin{array}{l}\text { molecular probe: } \\
\text { phospholipase } A_{2} \text { inhibitor }\end{array}$ & $\begin{array}{l}\text { marine sponge, } \\
\text { Luffariella variabilis }\end{array}$ & wild harvest of sponge \\
\hline $\begin{array}{l}\text { Vent }^{\oplus} \text { DNA } \\
\text { polymerase }\end{array}$ & $\begin{array}{l}\text { polymerase chain } \\
\text { reaction enzyme }\end{array}$ & $\begin{array}{l}\text { deep sea hydrothermal } \\
\text { vent bacterium }\end{array}$ & recombinant protein \\
\hline $\begin{array}{l}\text { Formulaid }^{\circledR} \\
\text { (Martek Biosciences, } \\
\text { Columbia, MD) }\end{array}$ & $\begin{array}{l}\text { fatty acids used as additive } \\
\text { in infant formula nutritional } \\
\text { supplement }\end{array}$ & marine microalga & cell culture \\
\hline Aequorin & $\begin{array}{l}\text { bioluminescent } \\
\text { calcium indicator }\end{array}$ & $\begin{array}{l}\text { bioluminescent jellyfish, } \\
\text { Aequora victoria }\end{array}$ & recombinant protein \\
\hline $\begin{array}{l}\text { Green Fluorescent } \\
\text { Protein (GFP) }\end{array}$ & reporter gene & $\begin{array}{l}\text { bioluminescent jellyfish, } \\
\text { Aequora victoria }\end{array}$ & recombinant protein \\
\hline phycoerythrin & $\begin{array}{l}\text { conjugated antibodies } \\
\text { used in ELISAs and } \\
\text { flow cytometry }\end{array}$ & red algae & cell culture \\
\hline Resilience $^{\otimes}$ (Estée Lauder) & $\begin{array}{l}\text { "marine extract" } \\
\text { additive in cosmetics }\end{array}$ & $\begin{array}{l}\text { Caribbean gorgonian, } \\
\text { Pseudopterogorgia elisabethae }\end{array}$ & wild harvest of gorgonian \\
\hline
\end{tabular}

\section{Exploring the Unknown}

Most of the environments explored for novel organisms containing unique chemicals have been those accessible by SCUBA. Although bioactive compounds have been identified from higher latitudes, such as the fjords of British Columbia and under the Antarctic ice, the geographic focus of "biodiversity prospecting" has been primarily the tropics. Aside from the fact that it's just more comfortable to dive in warm water, tropical seas are well known to be areas of high biological diversity and, therefore, logical targets for high chemical diversity. Marine biodiversity prospectors have focused on shallow water benthic environments-areas that can be accessed with relative ease by snorkelling and SCUBA diving. Collection of samples from deeper environments has been accomplished using closed-circuit rebreather diving, dredging and trawling, and submersibles. The focus of our drug discovery exploration program at Harbor Branch is deep water organisms that live on the continental shelves and slopes at depths from 130 to 1000 meters, i.e., beyond SCUBA depths, using our Johnson-Sea-Link manned submersibles. Submersibles provide platforms that enable us to go deeper, stay longer, access unusual sites that cannot be

accessed using conventional methods (e.g. steep walls, rocky bottoms, and vent communities), and be more precise and selective in our sampling than conventional deep-water collection methods permit.

There is still most of the deep sea yet to be explored. With rare exceptions (e.g. the analysis of deep sea cores to identify unusual microbes), the deep sea bottom, midwater habitats, and most of the world's oceans at depths greater than those accessible by SCUBA, have not yet been explored. The reason for this deficiency is primarily financial: oceanographic expeditions are expensive, and federal funding to support ship operations (e.g. University-National Oceanographic Laboratory System fleet support) is generally not available if the focus of the research is drug discovery. The National Science Foundation does not specifically support drug discovery, and the National Institutes of Health does not support ship operations. The National Oceanic and Atmospheric Administration/National Undersea Research Program has been the single exception, however, budget cuts to that program during the past few years have seriously curtailed funding for ocean-going research. Industry support for oceanographic expeditions and early-phase discovery research has been lack- 



Figure 3. MCF-7 human breast adenocarcinoma cells, viewed by confocal microscopy, nuclei (black arrows); "hair-like" structures (microtubules) which comprise the cytoskeleton (white arrows). A. Untreated cancer cells. B. Following treatment with the anti-cancer drug, paclitaxel, nuclei become fragmented and the microtubules form abnormal "bundled" filaments. These cells will eventually die. C. After treatment with discodermolide, effects are similar to paclitaxel but are much more pronounced. Nuclei are fragmented and microtubules are formed into severe needle-like "bundled" filaments. These effects induce rapid cell death (photomicrographs provided by Dr. Ross E. Longley, Harbor Branch Oceanographic Institution). ing; some pharmaceutical companies provide matching funds for less expensive SCUBA collections, but none provides support for oceanographic expeditions.

The President's Panel on Ocean Exploration, in responding to the President's directive for a national ocean exploration strategy (cited above), recommended the following: "Relevant federal agencies must ensure support for early phase research by establishing new programs specifically targeted for research for discoveries from the Ocean Exploration Program. In addition to the programs that currently exist to support shortterm, high risk research on the living and non-living "products" of exploration, federal agencies need to emphasize, prioritize, and fast-track research initiatives on these "products" of the Ocean Exploration Program. Private sector involvement is critical. Although mechanisms exist to support and encourage partnerships between industry, academia, and government (e.g. SBIR and STTR programs), these programs are not oriented to support the early phase research that is necessary to identify discoveries with commercial potential. Incentives should be provided to industrial sponsors of high risk, early phase, research. These incentives should include, but not be limited to, tax credits, grants and favorable licensing terms (NOAA, 2000).

\section{Political Considerations}

The exploration of new geographic areas will undoubtedly focus on areas outside of U.S. jurisdiction. Indeed, since most of the tropical seas-the areas of focus of most biodiversity prospecting-are under the jurisdiction of other countries, compliance with national and international regulations regarding access, extraction of natural resources, and exporting materials has been an essential element of marine natural products drug discovery to date. Working in a country's territorial waters, collecting samples and exporting those samples involves obtaining permits from and coordinating the interaction of several national and state agencies, e.g. defense, fisheries, and national parks, to name a few. It is often a lengthy process, and plans for foreign collections must be made several months or even years in advance of the expedition.

Balancing the responsibilities of the stewards of marine resources with the requests of marine bioprospectors is indeed a challenge. Environmental resource managers are charged with protecting their resources from overexploitation. Legislators and policymakers must decide whether bioprospecting is consistent with their plans for resource management. If they decide it is, they must draft and implement policies for access, use, and development of the resources.

Still unresolved, for the most part, are issues dealing with fair and equitable sharing of technologies and revenues related to the discovery and commercialization of products from marine resources. As a result of the recommendations of the United Nations Convention 
on Biological Diversity, legislators, bioprospectors, and environmental resource managers have begun to discuss what actually does constitute a "fair and equitable sharing." How does one place a value on a resource? If, for example, a drug was developed based on a chemical from an organism that is endemic to the country in which it was collected, should the revenue sharing be greater than if the organism occurs (and was collected) throughout a geographic region and across jurisdictional boundaries? If the organism is harvested to provide the materials for clinical development and commercialization, should the revenue sharing be greater than if only a few samples were collected to identify the active compound and subsequent supply was based on alternative methods? Since the answers to these questions are usually not known at the time an agreement must be negotiated to access the resources, the approach taken to date has been simply to agree upon a royalty to be paid by the bioprospector to the country. Expectations for the amount of such a royalty may sometimes be unrealistic, especially in view of the fact that pharmaceutical companies will generally agree to pay royalties of less than $5 \%$ of net sales to the licensor of the chemical. This is (perhaps unfairly) based on the industry average of $\$ 50$ to $\$ 200$ million to develop a drug, compared with the licensor's costs of perhaps less than $\$ 1$ million to collect the organism, test it for medicinal potential, add value to the compound by characterizing its physical, chemical, and biological properties, and protect its proprietary value by patenting the discovery. Undoubtedly, these considerations arise during negotiations to determine fair and equitable sharing between the bioprospector and the country of origin of the source organism. To be fair, neither party should be unreasonable in its expectations. Each party must recognize both the value added to the resource (and the revenue stream as a result of the value added), as well as the original, continuing, and perhaps intangible value of the resource as part of an ecosystem.

Of course, the chances of a drug being commercialized are very low, and the payoff could be several years from the original discovery. In the spirit of respect for, and acknowledgment of the scientific capabilities and contributions of the source country, alternative scenarios to revenue sharing may include more near-term. benefits, such as support for development of the scientific infrastructure (particularly for developing nations), training of students, scientist exchange programs, and technology transfer. These are often key elements in a revenue- and technology-sharing agreement.

\section{New Tools for Discovery}

To optimize our chances for identification of marine resources with medicinal potential, we must use the best tools for discovery at all stages: exploration of new locations, collection of organisms never before sampled, and identification of chemicals with pharmaceutical potential. Increased sophistication in the tools available to explore the deep sea has expanded the habitats that can be sampled and has greatly improved the opportunities for discovery of new species and the chemical compounds they produce. New and improved platforms (such as autonomous, remote, and humanoccupied underwater vehicles) to take us farther and deeper are in development. These platforms need to be equipped with even more sophisticated and sensitive tools (e.g. cameras, sensors, and manipulators) to enable us to identify an organism as new, to assess its potential for novel chemical constituents, and if possible, to non-destructively remove a sample of the organism. Tools and sensors that have been developed both for space exploration and for diagnostic medicine need to be applied to the study of the inhabitants of our last frontier on Earth.

Although there exist some specialized tools and chambers that allow deep water organisms to be maintained under ambient conditions, i.e. high pressure and low temperature, there is still a need for the development of versatile bioreactors that can be deployed and operated in extreme environments (e.g. hypersaline, vent, anoxic, and deep sea habitats). Such bioreactors could be used for collection, at-sea maintenance, and evaluation of both macroorganisms and microorganisms so that their metabolites could be studied under physiological conditions that are as similar as possible to ambient conditions.

Another approach to the identification of new products is the incorporation of miniaturized biosensors into both collecting tools and bioreactors for rapid, in situ analysis of marine organisms for bioactive molecules. A number of miniaturized biosensors and probes to study human disease processes are in development. Adaptation or development of new biosensors and probes for rapid, in situ screening of marine organisms would involve specialized tools, ideally for nondestructive sampling and analyses of the target organisms (Pomponi, 1999). Development of in situ biosensors would enhance our ability to probe the expression of metabolites in response to various stimuli, lead to a better understanding of the role of the secondary metabolites in nature, and perhaps provide clues to the potential biomedical utility of these compounds.

\section{New Models, New Paradigms}

The biological evaluation of marine-derived extracts and pure compounds for pharmaceutical development has been based on assays developed by the pharmaceutical industry for high-throughput screening of large libraries of synthetic compounds. They measure a number of end points, such as activation or inhibition of enzymes or receptors involved in human disease processes, inhibition of growth of human pathogenic microorganisms, and toxicity against human cancer cells (McConnell et al., 1994; Ireland et al., 1993; Munro 
et al., 1999). As our understanding of the biochemistry behind a variety of diseases has improved, better methods have been developed for rapidly determining the biomedical potential of the metabolites produced by marine organisms. None of the assays used in major pharmaceutical drug discovery programs, however, takes into account the role of marine-derived compounds in nature, i.e. the in situ biochemical functions of the metabolites, and how those functions may be applied to the discovery of new drugs and probes to study human disease processes.

Marine organisms as model systems offer the potential to understand and develop treatments for disease based on the normal physiological role of their secondary metabolites.

For example, the mechanisms of action of the toxins of Conus, the poisonous snail, are well-known (Hopkins et al., 1995), and are currently being applied to the development of new classes of drugs to treat diseases such as epilepsy.

Marine organisms have already demonstrated their utility as biomedical models, the results of which have been applied to understanding normal and disease processes in humans (Ocean Studies Board, 1999). Can we continue to apply this knowledge to our rapidly increasing understanding of the human genome and human disease processes? Or perhaps a more relevant question is this: can we use our rapidly increasing understanding of the human genome and human disease processes to guide our discovery of novel marinederived chemicals that can be used against newly discovered disease targets? Considering the evolutionary conservation of molecular signaling pathways, one can hypothesize that our understanding of molecular pathways and disease targets in mammalian systems can help us not only to elucidate the ecological roles of marine-derived metabolites, but can also provide a more rational approach to the discovery of drugs to treat a variety of diseases. How does a simple organism, like a sponge, through which seawater and associated bacteria, fungi, and viruses constantly flow, defend itself against microbial infections? How does it signal its cells to divide rapidly enough to heal a damaged surface in a few hours, or spread out over a substrate in a matter of days or weeks, yet control this proliferation so that the sponge itself does not get cancer? How, with only a primitive immune system, does it recognize an invading organism as "non-self" and send out chemicals to kill the invading cells, without killing its own cells? We know so little about these processes in the organisms from which we have identified literally thousands of chemicals with biomedical potential. Molecular tools and approaches that have been developed to understand similar processes in mammalian systems must be applied to understanding these processes in marine organisms. A multidisci- plinary approach-involving molecular biologists, pharmacologists, and chemical ecologists-to discovery of marine-derived drugs will likely result in the discovery of unique bioactive chemicals and new ways to address the treatment of human disease.

\section{Sustainable Use of Marine Resources with Commercial Potential}

With the enormous potential for discovery, development, and marketing of novel marine bioproducts comes the obligation to develop methods by which these products can be supplied in a way that will not disrupt the ecosystem or deplete the resource. Supply of most marine-derived compounds is a major limiting factor for further pharmaceutical development. Often, the metabolite occurs in trace amounts in the organism, and a steady source of supply from wild harvest cannot provide enough of the target compound for preclinical studies. In general, the natural abundance of the source organisms will not support production based on wild harvest. Unless there is a feasible alternative to harvesting, promising chemicals will remain undeveloped.

Some options for sustainable use of marine resources are chemical synthesis, controlled harvesting, aquaculture of the source organism, in vitro production through cell culture of the macroorganism or microorganism source, and transgenic production. Each of these options has its advantages and limitations, not all methods will be applicable to supply of every marine bioproduct, and most of the biological supply methods are still in development (Pomponi, 1999). The approach to be used will be based on a number of factors:

1. Complexity of the molecule: can it be synthesized using an industrially feasible process? Chemical synthesis of a compound gives the pharmaceutical company ultimate control in the supply of materials for clinical development and eventual marketing of the drug. Synthetic processes have been published for many marine bioproducts in development as pharmaceuticals (Corey et al., 1996; Harried et al., 1997). Unfortunately, most of these are multi-step processes that are not amenable to economic, industrial scale synthesis. To overcome this problem, major research programs are undertaken by the pharmaceutical industry to identify structurally similar compounds that are easier to synthesize, and perhaps even more potent, less toxic, and more bioavailable than the parent molecule.

2. Abundance of the organism in nature: what do we know about the impact of collections on the environment? Prior to large-scale wild harvest of an organism for recovery of a bioproduct, harvesting feasibility studies should be conducted. These 
should define factors such as the standing stock of the organism, its growth rate and the factors that affect growth, and the effects of harvesting and post-harvesting recovery of the target organism. These impact data should then be used to assess the potential of supply from wild harvest, and may also be useful in developing models for aquaculture of the source organism. Unfortunately, this is rarely done. One notable exception is the survey of the New Zealand sponge, Lissodendoryx sp., which produces the halichondrins, potent antitumor compounds in preclinical trials. The sponge is restricted in occurrence to one locality off the Kaikoura Peninsula. Research conducted by Battershill (1998), demonstrated that harvesting by dredging significantly reduced the standing stock of the sponge, but that the population may recover rapidly as a result of asexual propagation of sponge fragments dispersed as a result of the dredging. This study suggested that harvesting is only feasible for smaller quantities of the sponge.

\section{Source of the compound: is it microbially produced?}

A significant number of marine bioproducts with pharmaceutical potential have been identified from heterotrophic marine microorganisms isolated from coastal sediments (Fenical, 1993; Davidson, 1995; Kobayashi and Ishibashi, 1993). In addition, some marine bioproducts originally isolated from macroorganisms, such as sponges, have been subsequently discovered to be localized in microbial associates (Bewley et al., 1996; Sennett, 2000). If these microorganisms can be isolated and cultivated, optimization of production in marine microbial bioreactors could lead to an industrially-feasible supply option.

If the source of the compound is the macroorganism itself, development of in vitro production methods could provide bulk supply of the compound. Research in progress in our laboratory focuses on establishing cell lines of bioactive marine invertebrates that can be used as models to study in vitro production of bioactive metabolites and the factors which control expression of production (Pomponi and Willoughby, 2000). This could ultimately lead to in vitro production of marine bioproducts. More importantly, an understanding of the cellular and molecular processes that control production of these metabolites could be used to enhance culture optimization or to stimulate production of "unnatural" natural products, i.e. chemicals that the organism would not produce under normal conditions, but which may be more potent than the "natural" product.

\section{In situ growth conditions: is aquaculture an option} for deep-water organisms? Both in-the-sea and land-based aquaculture methods have been devel- oped for production of bioproducts from shallow water organisms. CalBioMarine Technologies (Carlsbad, California) has successfully aquacultured the bryozoan, Bugula neritina, the source of the antitumor compound bryostatin, and Ecteinascidia turbinata, the ascidian from which the antitumor compound, ecteinascidin 743 has been isolated (Figure 1). These are both common, shallow-water organisms for which reproduction and growth have been studied, but the factors controlling production of the compounds are not yet completely known. The New Zealand deepwater sponge, Lissodendoryx sp., is the source of the antitumor compounds, called halichondrins. The sponge occurs at 85-105 meters depth, but has been cultured successfully from cuttings on lantern arrays in shallower water, maintaining production of the bioactive halichondrins (Battershill et al., 1999). This indicates that aquaculture of some deep water sponges is feasible, however, species from deeper water may have more critical growth requirements, such as high pressure and low temperature. In-the-sea aquaculture is a cost effective method of production with opportunities for technology transfer and economic development in the source country, however, it may not afford the opportunity for complete control of environmental parameters or the over-expression of production of the compounds. Development of closed-system bioreactors for aquaculture of both shallow water and deep water organisms is a particularly challenging opportunity.

5. Biosynthetic pathway: is genetic engineering realistic for the compound? If the biosynthesis of the target compound is understood, it may be possible to identify, isolate, clone, and express the genes responsible for production of the metabolite in another host. In many cases, of course, biosynthesis of the product is not known, or it is a multi-step process involving several enzymatic reactions. For these cases, transgenic production is not a trivial process. Alternatively, chemoenzymatic synthesis, by which marine bioproducts are synthesized in cell-free, enzyme-based systems, offers a complementary technique to in vitro and transgenic production methods for marine bioproducts (Kerr et al., 1996).

\section{Summary}

The Ocean Studies Board of the U.S. National Research Council, in its review of the ocean's role in human health (Ocean Studies Board, 1999), rec ommended a greater focus on marine organisms as sources of new pharmaceuticals, new funding initiatives to support this effort in all therapeutic areas-not just cancer-and new interdisciplinary research and education programs to provide innovative approaches to 
marine based drug discovery.

Recent U.S. legislation and executive directives support a renewed emphasis on exploring the vast unknown areas of our oceans, discovering species new to science, identifying marine resources with potential medicinal value, and ensuring the protection and sustained used of these resources. We now have the unique opportunity to capitalize on new technological advances developed to explore the oceans of Earth and other planets, recent discoveries in medicine, molecular biology, and marine biotechnology, and a greater appreciation for benefit sharing and the value of marine resources to realize the full potential of our oceans and human health.

\section{Acknowledgments}

Drug discovery research at Harbor Branch Oceanographic Institution was supported in part by grants from the National Institutes of Health. Research on sustainable use of marine resources was funded by the NOAA Sea Grant Marine Biotechnology Program. I acknowledge the assistance of John Reed, Ross Longley, and Susan Sennett in preparation of the manuscript. I thank the Ocean Studies Board for their invitation, and I gratefully acknowledge the National Science Foundation, the Office of Naval Research, the United States Geological Survey, the Scripps Institution of Oceanography, and the Woods Hole Oceanographic Institution for their sponsorship of this lecture.

\section{REFERENCES}

Baker, J.T. and V. Murphy, 1981: Handbook of Marine Science: Compounds from Marine Organisms. Vol. II. CRC Press, Boca Raton, Florida.

Balandrin, M.F., J.A. Klocke, E.S. Wurtele and W.H. Bollinger, 1985: Natural plant chemicals, sources of industrial and medicinal materials. Science, 228, 11541160.

Battershill, C.N., M.J. Page, A.R. Duckworth, K.A. Miller, P.R. Bergquist, J.W. Blunt, M.H.G. Munro, P.T. Northcote, D.J. Newman and S.A. Pomponi, 1999: Discovery and sustainable supply of marine natural products as drugs, industrial compounds and agrochemicals: chemical ecology, genetics, aquaculture and cell culture. Menoirs of the Queensland Museum, 44, 76 (abstract).

Bergmann, W. and D.C. Burke, 1955: Contributions to the study of marine products, XXXIX. The nucleosides of sponges. III Spongothymidine and spongouridine. J. Org. Chem., 20, 1501-1507.

Bewley, C.A., N.D. Holland and D.J. Faulkner, 1996: Two classes of metabolites from Theonella swinhoei are localized in distinct populations of bacterial symbionts. Experientia, 52, 716-722.

Colwell, R.R., 1996: Microbial biodiversity and biotechnology. In: M.E. Reaka-Kudla and E. Wilson, eds., Biodiversity II: Understanding and Protecting Our
Biological Resources. Joseph Henry Press, Washington, D.C., pp. 279-288.

Corey, E.J., D.Y. Gin and R.S. Kania, 1996: Enantioselective total synthesis of ecteinascidin 743 . J. Am. Clem. Soc., 118, 9202-9203.

Davidson, B.S., 1995: New dimensions in natural products research: cultured marine microorganisms. Curr. Opin. Biotechnol., 6, 284-291.

Fenical, W., 1993: Chemical studies of marine bacteria: developing a new resource. Chem. Rev., 93, 1673-1683.

Harried, G.Y. , M.A. Strawn and D.C. Myles, 1997: Total synthesis of (-)-discodermolide: an application of chelation-controlled alkylation reaction. J. Org. Chem., 62, 6098-6099.

Hopkins, C., M. Grilley, C. Miller, K-J. Shon, L.J. Curz, W.R. Gray, J. Kykert, J. Rivier, D. Yoshikami and B.M. Olivera, 1995: A new family of Conus peptides targeted to the nicotinic acetylcholine receptor. J. Biol. Chen., 270(38), 22361-22367.

Ireland, C.M., B.R. Copp, M.P. Foster, L.A. McDonald, D.C. Radisky and J.C. Swersey, 1993: Biomedical potential of marine natural products. In: Marine Biotechnology, Vol. 1: Pharmaceutical and Bioactive Natural Products. D.H. Attaway and O.R. Zaborsky, eds., Plenum Press, New York, pp. 1-43.

Kerr, R.G., L. Rodriguez and J. Kellman, 1996: A chemoenzymatic synthesis of 9(11)-secosteroids using an enzyme extract of the marine gorgonian Pseudopterogorgia americana. Tet. Letters. 37, 8301-8304.

Kobayashi, J. and M. Ishibashi, 1993: Bioactive metabolites of symbiotic marine microorganisms. Chem. Rev., 93, 1753-1769.

Malakoff, D., 1997: Extinction on the high seas. Scicnce, 277, 486-488.

McConnell, O.J., R.E. Longley and F.E. Koehn, 1994: The discovery of marine natural products with therapeutic potential. In: The Discovery of Natural Products with Therapeutic Potential. V.P. Gullo, ed., ButterworthHeinemann, Boston, pp. 109-174.

Morse, D.E. and A.N.C. Morse, 1991: Molecular signals, receptors and genes controlling reproduction, development and growth: practical applications for improvements in molluscan aquaculture. Bull. Inst. Zool. Acad. Sin., 16, 441-454.

Munro, M.H.G., J.W. Blunt, E.J. Dumdei, S.J.H. Hickford, R.E. Lill, S. Li, C.N. Battershill and A.R. Duckworth, 1999: The discovery and development of marine compounds with pharmaceutical potential. J. Biotechnology, 70, 15-25.

NOAA, 2000: Discovering Earth's Final Frontier: A U.S. Strategy for Ocean Exploration. The Report of the President's Panel for Ocean Exploration, Washington, D.C., 61 pp.

Ocean Studies Board, National Research Council., 1999: From Monsoons to Microles: Understanding the Ocean's Role in Human Health. National Academy Press, Washington, D.C. 
Paul, V.J., 1992: Chemical defenses of benthic marine invertebrates In: Ecological Roles of Marine Natural Products. V.J. Paul, ed., Comstock Publishing, Ithaca, New York, pp. 164-188.

Pawlik, J.R., 1993: Marine invertebrate chemical defenses. Chem. Rev., 93, 1911-1922.

Pomponi, S.A., 1999: The bioprocess-technological potential of the sea. J. Biotechnology, 70, 5-13.

Pomponi, S.A. and R. Willoughby, 2000: Development of sponge cell cultures for biomedical application. In: Mothersill, C. and Austin, B., eds., Aquatic Invertebrate Cell Culture. Springer-Praxis, Surrey, England, pp. 323-336.

Radmer, R.J., 1996: Algal diversity and commercial algal products. BioScience, 46, 263-270.

Rinehart, K.L., T.G. Holt, N.L. Fregeau, J.G. Stroh, P.A. Keifer, F. Sun, L.H. Li and D.G. Martin, 1990: Ecteinascidins 729, 743, 745, 759A, 759B, and 770: potent antitumor agents from the caribbean tunicate Ecteinascidia turbinata. J. Org. Chem., 55, 4512-4515.

Roussis, V., Z. Wu, W. Fenical, S.A. Strobel, G.D. Van Duyne and J. Clardy, 1990: New antiinflammatory pseudopterosins from the marine octocoral Pseudopterogorgia elisabethae. J. Org. Chem., 55, 4916-4922.

Sennett, S.H., 2000: Marine chemical ecology: applications in marine biomedical prospecting. In: Marine Chemical Ecology. J.B. McClintock and B.J. Baker, eds., CRC Press, Boca Raton, Florida.

ter Haar, E., R. J. Kowalski, E. Hamel, C.M. Lin, R.E. Longley, S.P. Gunasekera, H.S. Rosenkranz and B.W. Day, 1996: Discodermolide, a cytotoxic marine agent that stabilizes microtubules more potently than Taxol. Biochemistry, 35, 243-250.

Winston, J.E., 1988: The systematist ${ }^{\prime}$ perspective. In: Biomedical Importance of Marine Organisms. D.G. Fautin, ed., California Academy of Sciences, San Francisco, pp. 1-6.

Wright, A.E., D.A. Forleo, G.P. Gunawardana, S.P. Gunasekera, F.E. Koehn and O.J. McConnell, 1990: Antitumor tetrahydroisoquinoline alkaloids from the colonial ascidian Ecteinascidia turbinata. J. Org. Chem. $55,4508-4512$.

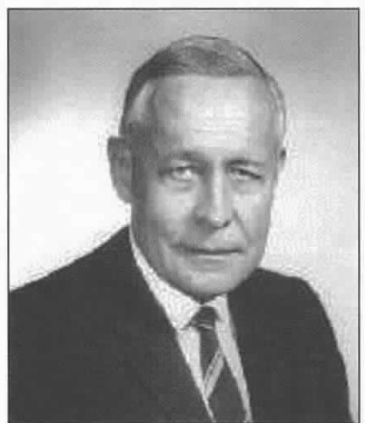

Dr. Roger Revelle
The Roger Revelle Commemorative Lecture Series was created by the Ocean Studies Board in honor of the late Roger Revelle. The speakers and topics are intended to highlight the important links between ocean sciences and public policy for a general audience. The lecture is held annually at the Fall meeting of the OSB in Washington, DC, and is open to the public. For more information about the Lecture Series and the Ocean Studies Board, see http://www4.nationalacademies.org/cger/osb.nsf/.

Sponsors:

National Science Foundation

Office of Naval Research

Scripps Institution of Oceanography

U.S. Geological Survey

Woods Hole Oceanographic Institution 